\title{
Practical aspects of mobilising property tax: experience in Sierra Leone and Malawi
}

Commonwealth Journal of Local Governance

Issue 16/17: June 2015

http://epress.lib.uts.edu.au/ojs/index.php/cjlg

\section{Paul Fish ${ }^{1}$}

Founder and Advisor

Revenue Development Foundation

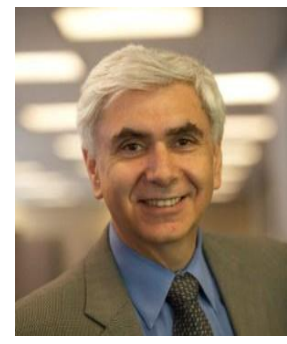

Much literature has been written about the appeal of property tax as a stable source of revenue for subnational governments in developing countries. Building on this significant background of literature is the author's practical experience working in local government institutions within both Sierra Leone and Malawi. This article relates to the development and testing of a process of mobilizing the internally generated property tax revenues of local governments, and reports on the results of that process, and the challenges and lessons learned.

Keywords: Property rating, Property taxation, Local Government, Valuation, Decentralisation, International Development, Sub-Saharan Africa

\section{Introduction}

Property tax is often cited as an attractive method of raising local revenues since much of the burden is borne by the people who live in the jurisdiction. Additionally unlike income, property is highly visible and importantly immobile. Thus there is a good appeal for the taxation of property value. In sub-Saharan Africa however property tax is rarely tapped as a source of significant local revenue. As one writer noted, property taxation is "one of the most lucrative ....yet least tapped sources of revenue to support urban government in Africa" ${ }^{2}$ One of the reasons cited for poor use is the high cost of administration. As one noted commentator states ${ }^{3}$ :

... in part, these low yields reflect failures in the administration of the tax. Many properties are missing from the tax rolls, or are inaccurately valued, and collection is extremely inefficient. There should be procedural reforms to improve coverage, the accuracy of valuation, and the efficiency of collection.

\footnotetext{
${ }^{1}$ Paul Fish is a Member of the Royal Institute of Chartered Surveyors (MRICS) and worked for nine years in Sierra Leone, developing and initiated the Revenue Mobilisation Program (REMOP) in seven local councils. One council in Malawi has also completed REMOP and a pilot involving three councils in Ghana has started. ${ }^{2}$ Charles Mou, "Major Property Tax issues in Africa" Property Tax in eastern and Southern Africa: Challenges and lessons Learned. Working Paper No. 2, (Harare: Municipal Development Program, 1996)

${ }^{3}$ William Dillinger, Urban Property Tax Reform: Guidelines and Recommendations. World Bank Urban Management Program. Tool No 1. (Washington DC: World Bank 1991
}

(C) 2015 Paul Fish. This is an Open Access article distributed under the terms of the Creative Commons Attribution 4.0 Unported (CC BY 4.0) License (https://creativecommons.org/licenses/by/4.0/), allowing third parties to copy and redistribute the material in any medium or format and to remix, transform, and build upon the material for any purpose, even commercially, provided the original work is properly cited and states its license. 
The Revenue Mobilization Program (REMOP), developed by the author and implemented in several subnational governments, seeks to address the high costs by using modern technology and developing a recording structure to capture all properties, simplifying and automating the valuation process, employing computer aided mass valuation, and enhancing both the collection and the enforcement of the tax.

A central guideline for the practical development of the REMOP has been the reported experience of Kelly ${ }^{4}$ in East Africa. Kelly refers to four essential lessons.

1. Property Tax reform must be comprehensive, linking
a. property information,
b. valuation assessment,
c. collection, and
d. enforcement.

2. Stakeholder education is essential and should be linked to customer service

3. Mass valuation should be introduced

4. Sustainable revenue mobilisation is essential and requires
a. institutionalised administration procedures
b. political will
c. strong local capacity

The author has been implementing the Revenue Mobilisation Program (REMOP) over a nine year period from 2006 to 2015, using as a foundation the lessons learned and reported by Kelly.

The following local governments have been part of the REMOP:

\section{Sierra Leone}

1. Makeni City Council

2. Bo City Council

3. Bo District Council

4. Kailahun District
5. Koinadugu District Council

6. Kono District Council

7. Koidu New Sembehum City

8. Pujehun District Council

\section{Malawi}

1. Mzuzu City Council

\footnotetext{
${ }^{4}$ Kelly, Roy (2000) Property Taxation in East Africa. Lincoln Institute of Land Policy
} 
This paper describes the programme, reviews the experiences of implementation in a number of councils, and highlights the revenue results achieved. In conclusion the paper considers the challenges encountered and how they can be mitigated.

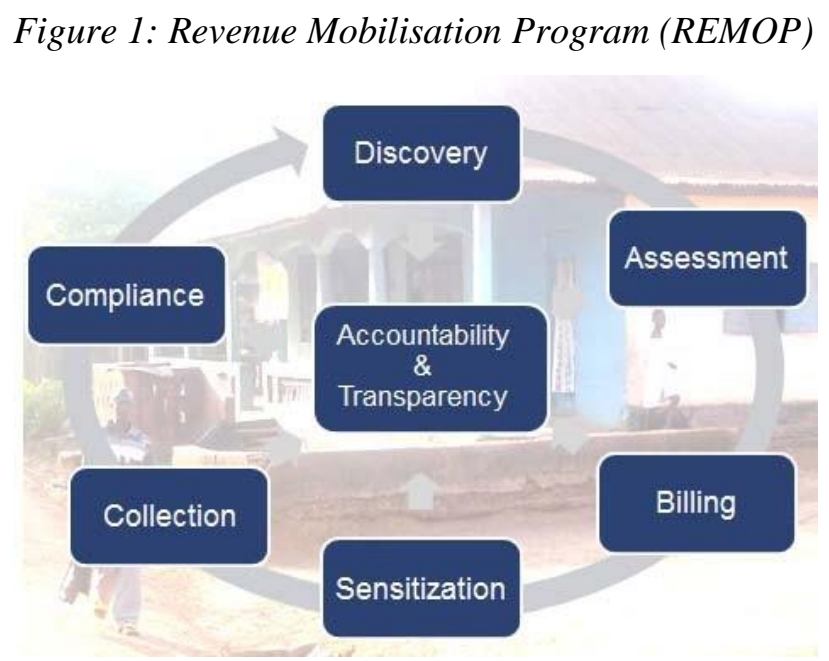

Figure 1 illustrates the annual cycle and the six distinct components required to ensure a transparent and accountable revenue mobilisation process. It is important at this stage to emphasise that REMOP is an annual recurring process, and not simply a single cycle activity.

Prior to any implementation it is of course critical to have the total commitment of the local council members and its administrators. An overview of the program and the stated goals are presented and an agreement to adopt requires a Council resolution. Of particular importance at this preliminary juncture is the acceptance by council of the more difficult Compliance stage to be implemented later. It is important for the council to acknowledge that the Program may challenge high profile community members who default on the obligation for payment of their rates. A council information session is key with an open interaction between the implementation and training staff. Other stakeholders need to be informed such as relevant central government ministries and departments.

\section{Discovery: the capture of assessable properties}

A complete discovery or capture/study of all properties to be assessed is required to achieve a complete inventory of buildings within the boundaries of the local council authority. An accurate collection of relevant data for each property is required. A partial or inaccurate discovery phase will fail to win the confidence of taxpayers. Street names and unique house numbers must be assigned so that buildings and their owners can be physically identified and located. Street name signs are vital but expensive and subject to vandalism. Painting the name on the first and last house can be acceptable. 
This initial discovery stage describes the property information that has been acquired and clarifies the practical steps needed to underpin the assessment.
a. What property to tax?
b. Undertake satellite imaging / GIS work to guide the complete collection
c. Record a unique identification of each assessable property
d. Complete relevant data fields
e. Complete personnel Training and supervision arrangements

\section{a. What property to tax}

Decisions on what properties to tax and what to exclude is typically outlined in legislation. Various pieces of African legislation studied, including in both Sierra Leone and Malawi, seem to direct that all properties are to be taxed, and should include land and buildings held either privately or publicly. Exclusions typically relate to religious buildings eg: churches or mosques, public hospitals or schools.

For practical reasons the local councils in Sierra Leone and Malawi accepted the author's recommendation of vacant land exclusion. The main reason for vacant land exclusion is the extraordinary difficulty in identifying the owner with consistency since there is often an absence of formal registry of title records. Additionally vacant land has a relatively low value compared to land with buildings. Since the potential tax amount is thus small for land and the costs of implementation high, these reasons were considered to outweigh the benefits of taxation.

\section{b. Undertake Satellite Imaging/GIS}

Satellite imaging/GIS is essential to ensure a satisfactory and complete discovery phase. The following lists the direct advantages in terms of data collection, but other indirect advantages relate to collecting data that can be used for other departments in particular town planning.

- Identification of municipal and ward boundaries

- Identification of buildings captured

- Identification of and codification of street forms or clusters of buildings

- Printing of scaled maps to guide the field work

- Visual verification of taxable properties with owners

- Later statistical analysis by location, e.g. paid or unpaid taxes, average and total tax, compliance rates. 

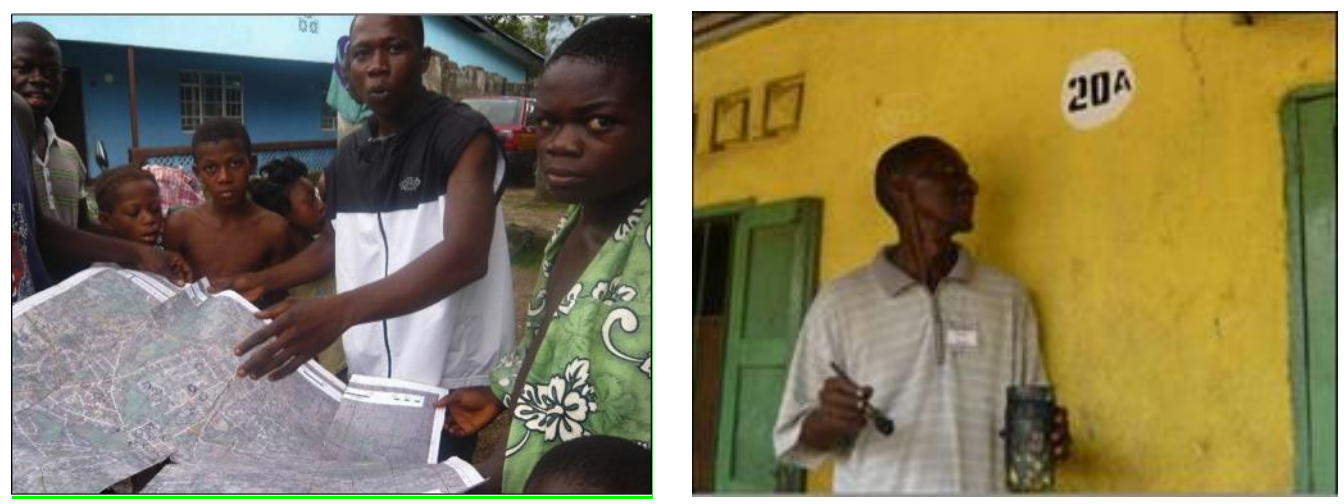

\section{c. Building identification}

A unique identifier for each building is critical not only for recording purposes but also for visual reference to enable delivery of documents. A number is assigned by a data collector during fieldwork and physically identifies all taxable buildings with the aid of GIS work. The number assignment is guided by the GIS work and is painted on the building for future reference. Adequate reserved numbers are allowed for future buildings where there is vacant land.

\section{d. Data fields}

Adequate data fields are gathered with a focus on features of the building that will have an effect on the valuation. For example whether the building has access to electricity or water. A standard form is used as the data instrument for fieldwork. The data includes a measurement of the exterior walls so that the area can be calculated. Illustrated in the Appendix is an example of the domestic form used for Mzuzu in Malawi. The forms are designed according to local needs and the features in each jurisdiction may well be different. The appropriate features are determined from discussions or a forum of local valuers, estate agents, and administrators.

\section{e. Personnel and Training}

It is unlikely that there are sufficient numbers of trained and available valuers in councils throughout subSaharan African countries. Thus the most expedient way to undertake the fieldwork is to use the local young workforce. Activities outlined above in c) and d) can be trained and then tested adequately with supervision. Moreover use of an area-based valuation process, as described below avoids the need for expert fieldwork. 


\section{Assessment}

In mature economies the value of property is set on the basis of a "market value" known as ad valorem. In most African settings, however, this is neither practical nor feasible given:

- the lack of an active or a transparent property market against which the assessed properties can be measured

- the limited professional valuation capacity in-country.

An alternate method is to use an area-based approach where the area in square meters of each building forms the basis of the valuation. The area-based approach is often criticized due to the bias in favour of higher quality buildings and is thus regressive favouring the more wealthy. The REMOP valuation however adopts the area-based approach but introduces a number of building features that can add or detract from the value and thus the desired progressivity of the property tax is achieved.

For simplicity, objectivity and fairness the REMOP assessment uses an adaptation of the area-based approach. This is called the "points based" approach. The area of the building is expressed as points. The process then assesses features of the property to adjust the points awarded for area alone. For example the REMOP would reduce the points value for a house without sanitary facilities, or increase the points value for a house with concrete walls compared to mud brick walls. A sample valuation is presented as an appendix, shown as part of a rate demand notice. In this way the higher quality and more valuable buildings are recognised to have a greater value, and thus progressivity is maintained. The points-based approach is recommended (Dillinger 1993) where the tax amounts are small and the costs of employing a professional valuer are high.

Potential for automation is the strongest reason for the adoption of the points-based approach. The points awarded are reduced to a simple formula and are then repeatedly and uniformly used for all valuations. Thus an automated mass-appraisal requirement can be achieved. The fact the that system relies on nonsubjective characteristics (i.e. awarding points to features that can be easily observed) helps ensure that the valuations are perceived by taxpayers as being fair and equitable. Moreover appeals against the valuation are based on the easily-observed features, are easier to explain, and so stimulate confidence.

The main critique of the points based approach is the arbitrariness of the points. However any distortions can be remedied by reference to a harmonisation study. A harmonisation, correlating the points values with a small sample of market values is possible. In Malawi the REMOP points value was harmonised with a sample of market values so that the value progression mirrors the small but observable property market. The graph shown below shows the results of the harmonisation where the correlation coefficient is calculated at 0.83 . 
Figure 2: Harmonisation

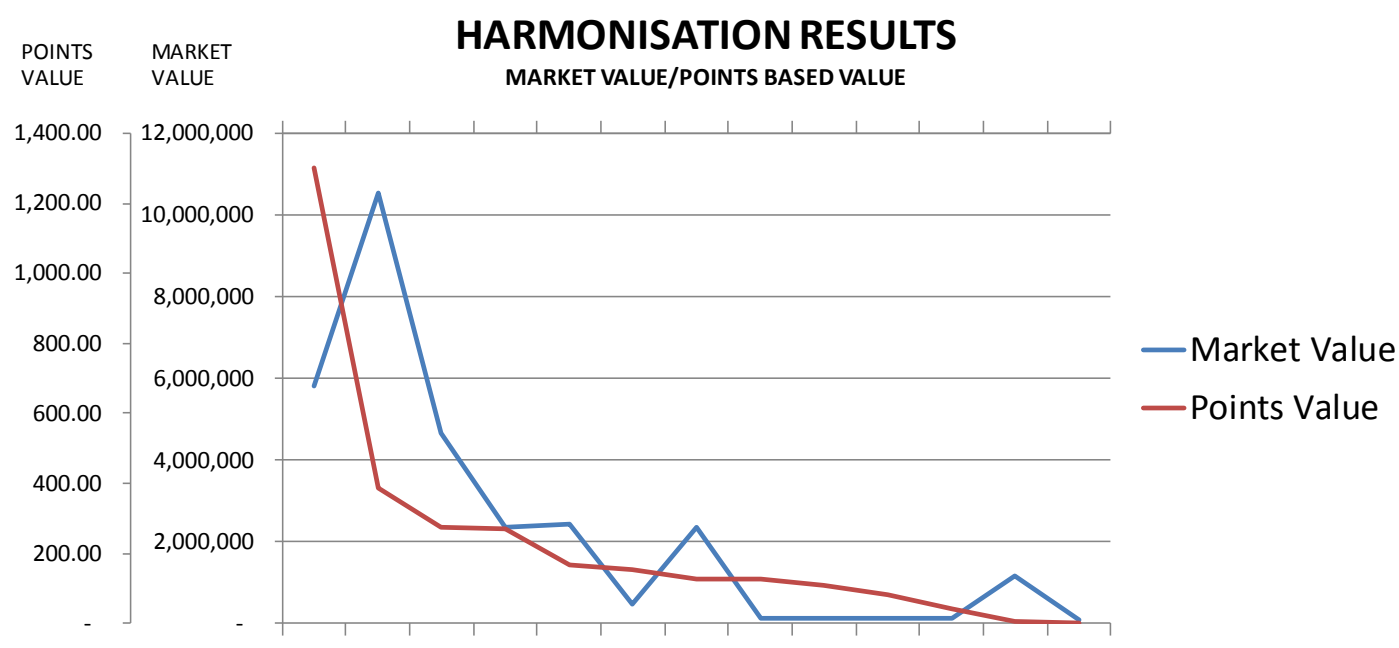

\section{Billing the property tax}

Information collected during the discovery and assessment phases is entered into a specifically designed modern software database. The software automatically generates the valuation as well as the printing of rate demand notices, which are then systematically but arduously delivered by hand to all taxpayers.

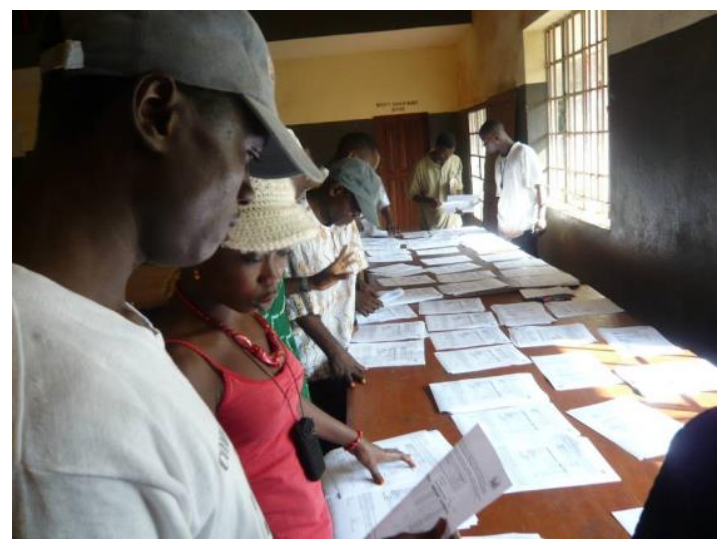

The billed amount for each property requires a uniform rate (Mill Rate) for each class of property that converts the assessed value into tax. Tax amount $=$ Value $x$ Mill Rate

So for example Mzuzu City Council in 2015 has set a uniform domestic mill rate of 165 for each valuation point. Thus the tax for an assessed house having a value of 500 points would be calculated as:

Value $500 x$ mill rate $165=$ Tax amount of MWK82,500

It is ultimately the councilors who resolve the mill rate based on the required municipal work budget, and balanced with the affordability of the tax to individual taxpayers. 


\section{Publicity}

Public awareness campaigns are necessary to encourage citizen engagement. Council leadership both administrative and polity are expected to take a leading role. The publicity explains to residents the purpose of the REMOP, the upcoming steps and importantly the basis of their tax liabilities, informs about rights (e.g. the appeals process) and obligations of Council and residents. The link between taxation and the benefits of development requires a constant and repetitive message. A clear explanation with examples are needed.
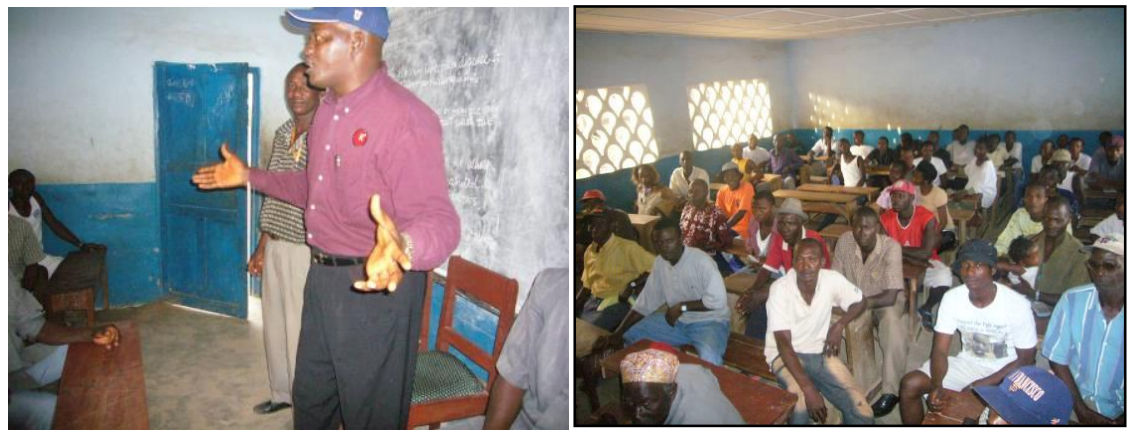

A variety of publicity media have been used in participating councils including radio programming, weekend public ward meetings in local schools and other venues, street theatre using youth groups, street banners, newspaper articles, announcements at local mosques and churches, and even the use of an official municipal town crier. Although a campaign is necessary throughout the six steps, intensity is raised during the collection phase.

The majority of revenue comes from a small band of more wealthy tax payers and a focused publicity campaign aimed at this group is worthwhile. In Mzuzu, Malawi the top 100 of the tax payers shoulder $30 \%$ of the potential revenue. These taxpayers are frequently the business leaders in the community. Thus a special information meeting with this invited group to meet the Council and encourage support will lead to improved participation. Civil Society organisations will contribute to the awareness campaign with active participation. They can also be encouraged to pressure the Council to improve transparency and to pressure the Council to undertake public works.

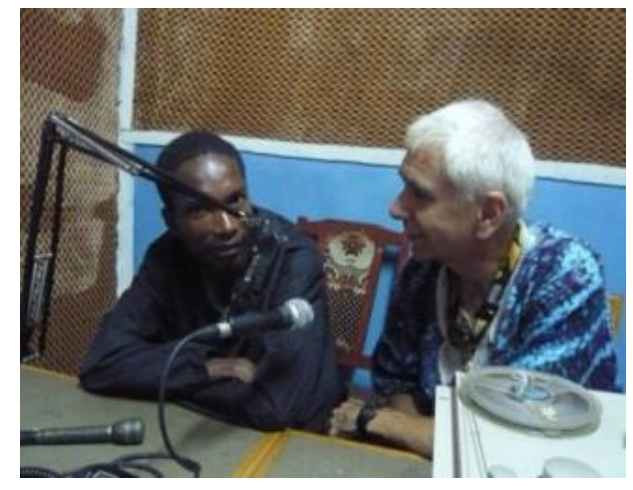

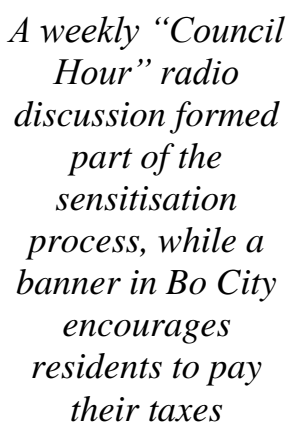

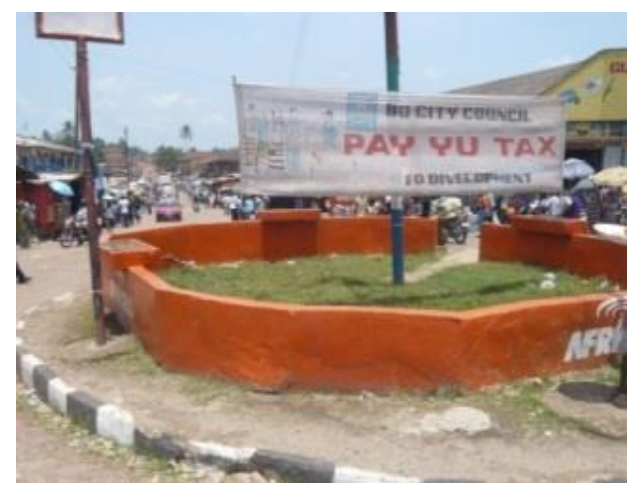




\section{Collection}

Traditionally local councils have used revenue collectors to coerce cash from residents on a door-to-door basis. This method tended to be focused on the vulnerable poor and marginalised who are often fearful of authority. This approach gives rise to corruption opportunities and can be a roadblock for progress. The REMOP process limits payments solely through commercial banks or local financial associations. This system helps to reassure residents that funds are being handled in a transparent manner and ensures that recording of payments is made more accurately.

The payment is made at bank branches where the tellers have been trained to recognise key data from the rate demand notice and to record on a customised deposit slip the unique REMOP identification number of the property, the street address and name of the owner. Reconciliation is made with council records on a daily basis. The customised deposit slip copy also acts as an official receipt so that the property owner can maintain for their recording.

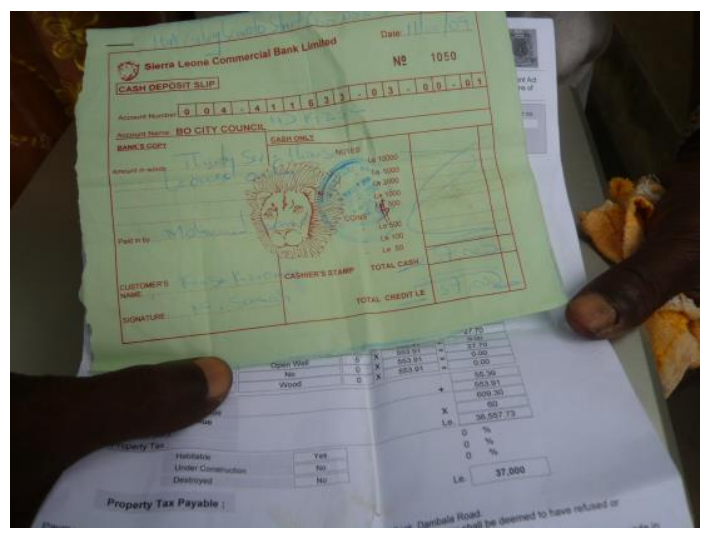

In Mzuzu, Malawi the bank was encouraged to open a branch at the civic office not only for property tax but for all council deposits. In this way the accurate recording of payments is made at both the bank and council. Moreover the confidence for taxpayers is that the council is receiving the tax efficiently. In rural districts of Sierra Leone the banks are more distant from the larger towns. In these areas a smaller Financial Services Agent (FSA) is appointed and linked with a bank. The FSA collects the deposits payments of Council rates which are then transferred in bulk. The use of mobile banking and even phone banking have been discussed and need to be investigated further as a viable way for depositors to have confidence that the payments are credited to the council account. 


\section{Compliance}

Enforcing compliance is crucial to establishing the legitimacy of the system. As described above, knowing that other taxpayers are also paying or are required to contribute to a tax system that benefits the whole community is a necessary condition for ensuring compliance. Enforcement does ultimately involve taking court action against defaulters, summoning defaulters to the local magistrate's court, but an effective intermediate stage involves the notification of defaulters through a lawyer's letter about pending legal proceedings. In practice, enforcing compliance has proved to be one of the most difficult aspects. Councils have faced entrenched interests, as the wealthiest property owners - from whom the majority of revenue would be received - are often highly influential with close connections to local political leaders. As will be discussed in the next section, the political will of local councils to enforce compliance is perhaps the single most important factor determining success or failure of revenue mobilisation efforts. Although the task of compliance should be left to administrators, an important factor is the strength of the political leadership to guide and support the process.

\section{Summary}

The REMOP program has focused on the comprehensive and practical aspects of the six stages outlined above. What has been important is that all of the stages are coordinated as a single project and undertaken in a specific order; a time consuming task not well suited to many funding agencies, but nonetheless critical to the success. An important issue to bear in mind is that the institutionalisation of the process takes at least two annual cycles until the process is fully embedded, the local council fully appreciates the results and assesses the effort of REMOP worthwhile. The key for the REMOP program is the careful coordination of all steps in the process delivered over a two-year period for sustainability. Overall, the REMOP manages to establish a system that is uniquely tailored to the local development context. The points-based mass valuation system lacks the usual tradition of market value assessment but is sophisticated enough to ensure progressiveness in the valuation, and is simple enough to be rapidly implemented, automated and managed locally. Jibao and Prichard (2013, p.13) comment on the Makeni example state that "while none of [the] elements were particularly unique in broad terms, it was the details of their operationalisation - with a focus on simplicity, transparency and low-cost - which was viewed as crucial to the potential for success." 


\section{Results and Evidence}

Overall, the REMOP program has seen encouraging improvements in the capacity of local councils to raise revenues in an accountable and transparent manner. This is evidenced by the increase in local revenue raised by local councils where REMOP has been implemented since 2006.

This section proceeds in three parts. The first assesses the revenue achieved by the local councils, using data available from computer records. The second provides a brief description of each council's experience. The third part describes other potential benefits and essential lessons when moving forward.

\section{Local revenue achieved}

The local revenues achieved are illustrated in the charts below where the computer records are available. The charts are arranged in the order in which the REMOP intervention was introduced. While the potential local revenue from these poor populations is small in real terms, the notion of civil society contributing to the benefits of the community have been embedded. The notion of contribution to a common purse encouraging good governance, and thus development, is regarded as positive. It is worthy of note that in Sierra Leone the widespread outbreak of ebola virus has seriously disrupted all local administrations and thus 2013/2014 revenues have been significantly affected.

\section{Makeni City Council}

Makeni City Council was the testing ground for revenue mobilisation in Sierra Leone. Jibao and Prichard (2013, p.30) trace the origin of property tax reform to the author's work in Makeni:

The first example of rapid improvements in local tax collection generally, and in the collection of property taxes specifically, began to emerge in Makeni literally within weeks of the arrival of VSO volunteer Paul Fish. Within a year... the entire apparatus of property tax collection had been substantially transformed, with corresponding gains not only in revenue collection, but also in the perceived legitimacy of the tax system.

In late 2006 Makeni City Council requested a model for improving property tax. Almost no revenue was earned in 2006 and the Council was starved of resources. During 2007 a small amount of support funding for the REMOP program was made available from the NGO Care and the early stages of discovery were initiated. During the following years the remaining parts of the cycle were implemented, namely the billing, collection and compliance phases. Revenues increased significantly. The figures shown below are sourced from the computer records. 
Figure 3: Makeni City Council revenue

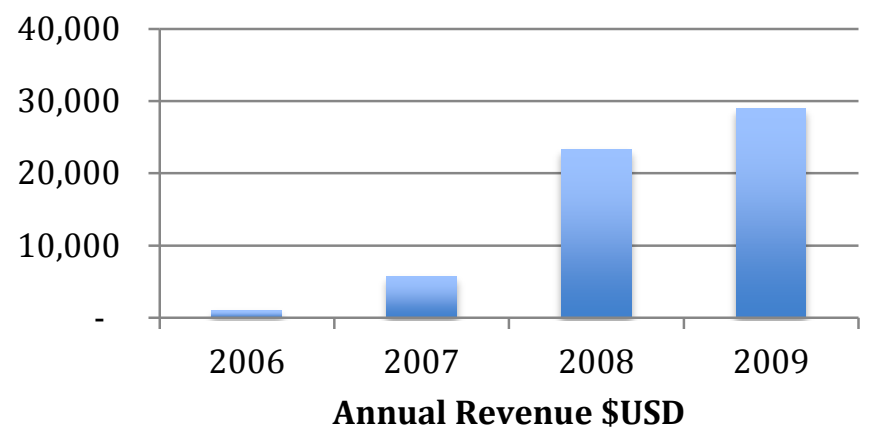

Despite this strong initial performance, the gains were not sustained. The changes introduced to the property tax system in 2007 Makeni are no longer in place, having been circumvented by local administration with entrenched interests. Others noted that while the local council was very supportive of efforts to expand the property rolls, it proved unwilling to enforce compliance given the political sensitivities involved. More recently a model based on the REMOP program was installed to revive the property tax. Later reimplementation under a UNDP sponsored program, copied the method developed by the author did revive the program, although the later parts of the program remain outstanding. Overall, the importance of REMOP work in Makeni may lie less in the actual revenue generated, and more in developing and testing a viable model that has been subsequently adopted by other councils across Sierra Leone.

\section{Bo City Council}

Prompted by the initial success in Makeni, the Sierra Leone Ministry of Finance, Local Government Finance Department requested an extension of the service to Bo City Council, the second largest city in Sierra Leone with a population of 250,000. Here the introduction of the REMOP was effective, with the added strength of a popular mayor - Wusu Sannoh who supported the program. The first full year of the REMOP in 2010 yielded strong results and the program is still supported today, although precise figures have not been obtained.

Figure 4: Bo City Council revenue

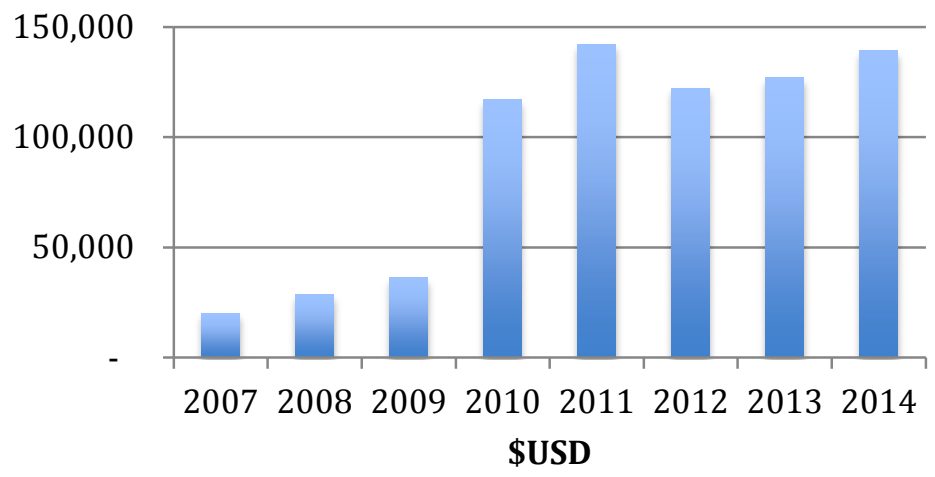


Unlike Makeni, the significant gains in Bo City Council have been sustained over time (see also Jibao and Prichard 2013). The political leadership of Bo displayed the necessary commitment to enforce compliance of the new tax system, and to overcome entrenched political interests, both among council staff members and residents of Bo. The author identified high levels of support from the mayor and other local leaders as key factors contributing to this success. Importantly, Bo City Council has been commended for the way in which it has strengthened its tax system while emphasising voluntary compliance over coercion (Prichard et al 2011). The efforts to encourage "consensual" taxation are reflected in two strategies - first, ensuring that tax enforcement followed clear and transparent rules; and second, extensive efforts to inform residents about how the revenue was being used by the council. Particular efforts have been made to link tax revenues to the new municipal bus service, for example. The new revenues have helped budget for new buses, waste collection and street lighting, among other services. Interviewees also suggest that grants from the World Bank have been easier to obtain with evidence of additional local revenues to help maintain projects.

\section{Bo District Council}

The Bo District Council was the first of the rural districts to request a model to mobilise property tax revenue. Similar to Bo City, the key to the success and promotion of the program was the strong support of the head of the council, the Chairman Joseph Bindi. Bo District includes the periphery of the Bo City area. This sharing of boundaries was brought into sharp focus by the councils' respective abilities to collect tax, and potential disputes arose.

Figure 5: Bo District revenue

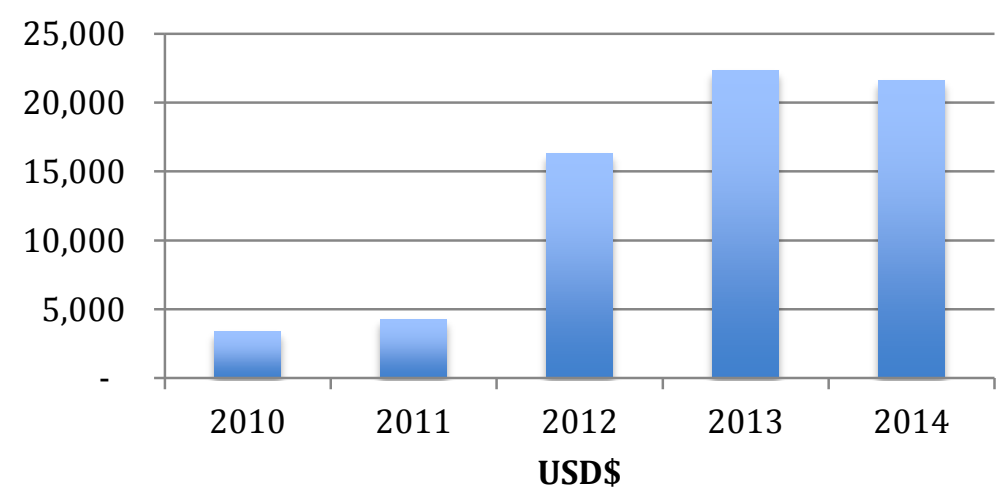

Bo District Council's revenue mobilisation efforts were supported by both VSO and Welthungerhilfe. The project began in 2011, and in 2012 the council issued its first rate demand notices. The council managed to collect revenues of US\$17,900 from over 6,000 properties, up from US\$2,500 in the previous year. 
While modest in absolute terms, this demonstrates a remarkable improvement in the first year. Council staff emphasised the fact that national elections took place in 2012, which dampened the political will for enforcement. Revenues were expected to be significantly higher in 2013, with the ongoing identification of properties and increased enforcement through the local magistrate court.

The revenue mobilisation efforts appear to have strong political backing from the district council Chairman (a view supported by nearly all interviewees). The Chairman, Mr Joseph Bindi, believes that the new taxation could substantially boost council revenues, potentially exceeding what they receive from central government. The District Council is conscious of the need to foster voluntary compliance by linking taxation to development. The chairman described an explicit strategy of targeting development projects in areas with the highest rate of compliance, at least in the early stages of the new system, to reinforce this behaviour.

Challenges do remain. Conflicts have arisen between the council and local chiefdoms as to who is responsible for collecting property taxes ${ }^{5}$. Disagreements with chiefdoms have reportedly led to "interference" in some areas, with local leaders actively encouraging non-compliance. The district will also face challenges in expanding revenue collection from the peri-urban areas bordering Bo city to more remote rural areas with lower concentrations of high-value housing and commerce.

\section{Koinadugu, Kailahun, Kono District Councils and Koidu City Council (KKKK)}

The previous work in Bo and Makeni drew the attention of The International Fund of Agricultural Development (IFAD), since they were working in the easterly part of Sierra Leone. IFAD's main programs of agricultural aid were closing and they needed a revenue model for local councils so that the new IFAD approaches would be adopted locally and funded from local revenue. In 2011 the author was awarded a contract on behalf of the newly formed organisation Revenue Development Foundation (RDF) to undertake a REMOP in four Local Councils.

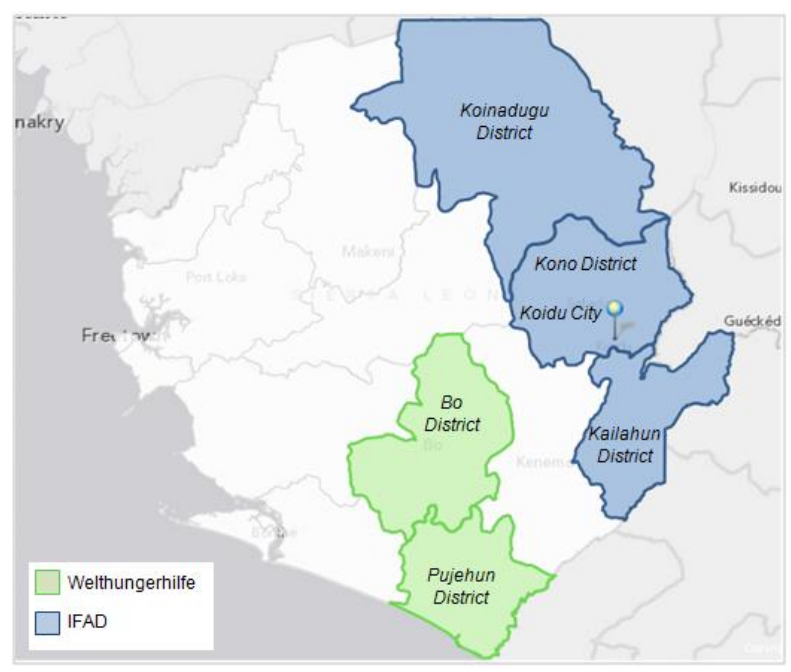

Figure 6: KKKK councils

\footnotetext{
${ }^{5}$ While chiefdoms are responsible for collecting the local ("poll”) tax, the Local Government Act (2004) clearly assigns the statutory duty for collecting property tax to the local councils.
} 


\section{Figure 7: KKKK revenue 2013}

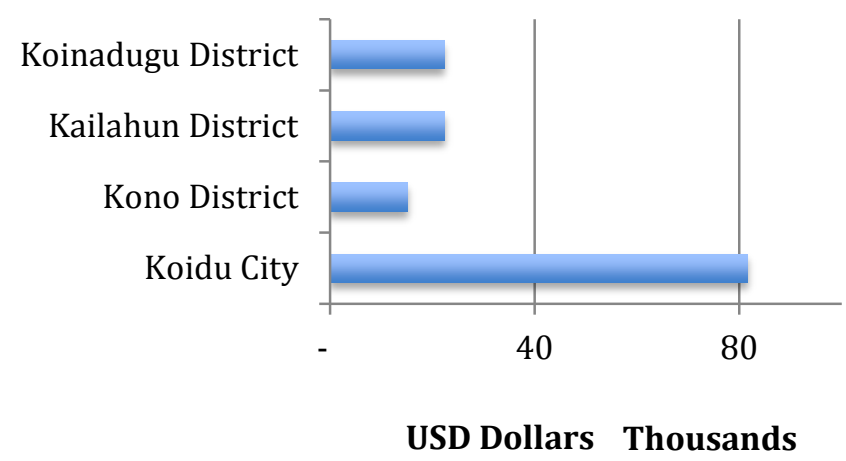

Despite extreme challenges in these remote areas, the first year of the tax cycle, 2013 proved a good test and initial results exceeded expectations. The initiation of a property tax concept in a previously untested area was a surprising success to the heads of each of the participating Councils. Development in these areas has been limited and is a longer-term objective that will be prompted by civil society pressure. Unfortunately the 2014 outbreak of Ebola, and the magnified effects on the local economies resulted in an effective shutdown of local administrations, especially in the latter part of the year. This year (2015) the Councils have requested further IFAD support to restart the process.

The implementation of the program was tested in these quite remote parts of the country. The obvious poverty of the Eastern province of Sierra Leone is greater than the rest of the country and thus affordability must be questioned. Challenging geography, in particular in the rural districts, means that the terrain is difficult with unmade, sometimes impassable roads, and thus the towns are difficult to access. Traditional authorities, the local Chiefs, command particular respect, and including this body of society into the program effectively has been a critical element, in particular for the rural communities.

A common feature of these KKKK councils is the political strength of the council and in particular the mayor or chairman of the polity. The support of these figures drove the initial acceptance of the program, in particular among the community and business leaders. The longer-term sustainability of the property tax revenue will depend on development of projects that benefit the community and at the time of writing this has not yet been initiated although it has been much discussed. 


\section{Mzuzu, Malawi}

The first REMOP implementation outside of Sierra Leone commenced in the latter part of 2013 with the first program ending in June 2015. Mzuzu City is the Northern Region capital with a population of 220,000. The Council had an existing system of property tax but the administration was keen to improve revenues through broader coverage, improved valuation, and greater compliance. An initial 10 month project was funded by a German NGO, German Development Cooperation (GIZ) and extended funding for an additional 14 months by German Federal Ministry for Economic Cooperation and Development (BMZ). The main thrust of the funding was an exit strategy for existing projects that were soon to close.

The results of the first full REMOP year (2015) were very successful where there was more than double the revenue collected in 2014. The REMOP discovery process now captures almost 40,000 properties compared to the previous 10,000 under the former system. Improved transparency, coverage, appeal methods, banking system and, at the time of writing, the active prosecution of defaulters are all factors that have contributed to the improvement in revenue generation.

Figure 8: Mzuzu City property tax revenue

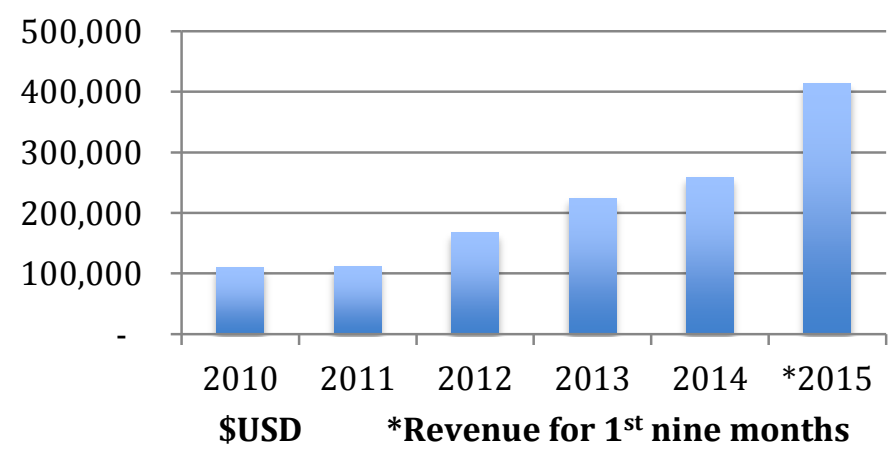

Challenges remain in the engagement of civil society to pressure local councils to provide benefits through improved city services. The REMOP valuation method by a system of points requires legislative changes to be formally approved, but there are entrenched interests at central government level who need to be convinced of the merits of the revised approach. Other local Councils in Malawi have expressed a serious interest in implementing REMOP, but these central government hurdles need to be addressed. 


\section{Figure 9: Mzuzu properties map}

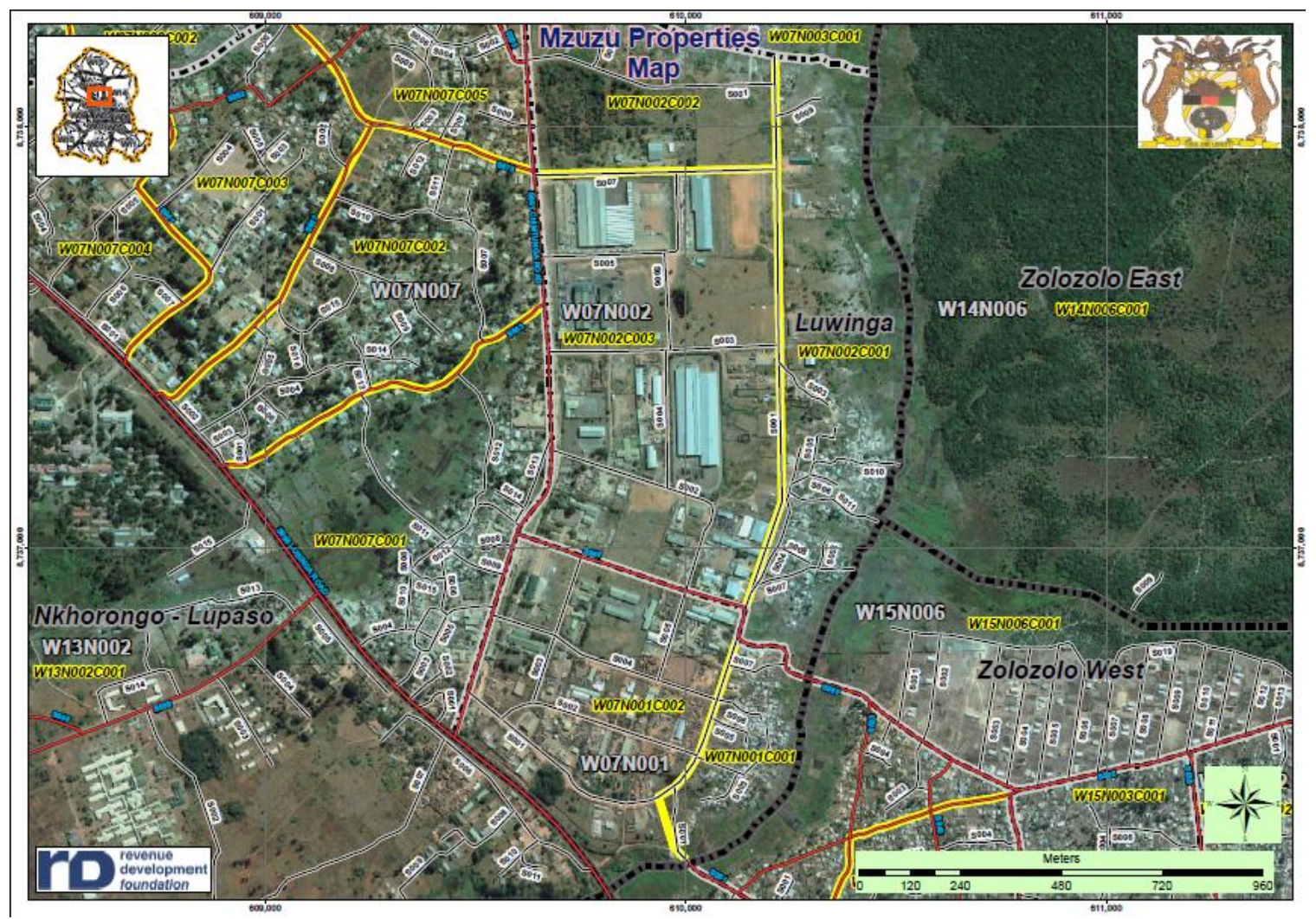

\section{Conclusions}

Through the experience of these councils we can conclude that revenue mobilisation using property tax is possible and can be sustainable. The amounts of revenue are initially quite small in real terms, in particular where the jurisdiction is a rural area with a challenging geography. However when the social contract with residents is encouraged, political leadership is effective, and councils achieve demonstrable improvements in service delivery, then a move to increase the level of taxes can be contemplated.

The implementation of the REMOP process closely follows the four lessons reported by Kelly (2000) where firstly a comprehensive holistic approach is taken to link the essential elements of property information with the valuation assessment, the collection and the enforcement. Secondly stakeholder education is made an essential element. Thirdly, that a vital mass valuation is achieved to significantly reduce the administrative costs. And lastly political will, institutionalisation and capacity building is driven by the success and power of the new revenue mobilisation. 
The low administration cost is a significant benefit of the REMOP program. The automation offered by the dedicated REMOP software, coupled with a simplified but highly transparent valuation method, reduces the costs by a large proportion. The ad valorem market approach that is commonly used is difficult to justify in terms of higher administrative cost, the relatively low tax amounts generated and the requirement for high-level expertise. While the area based approach has been criticised for its lack of progressivity the REMOP adaptation of the area-based approach simplifies the administration and does lead to a progressive taxation and importantly can be harmonised with market value.

The political adoption of property tax through this method is essential. It requires strong, well-informed political leadership and must be open and transparent in its approach. The transparency of the process; it's comprehensive approach, the inexpensive administration costa, and the use of an automated mass valuation method all contribute to making the REMOP model a sustainable and transferable system for local revenue mobilisation. 


\section{Lessons Learned and other potential benefits}

There are a number of key lessons learned plus some unintended benefits experienced in the implementation of the REMOP which should be used to influence and strengthen its use in the future.

1. Political issues have to be resolved at the outset. Most Councilors are keen to earn revenue for the community, but taxing influential residents and even contemplating summoning them to court if they default is an anathema. A strong leadership with commitment from the political head to support the REMOP is critical. A project was commenced in Pujehun District Council and proceeded to the collection phase. The project did not survive due partly to administrative failures, but more importantly the lack of a fully supportive political head of the council.

2. All six stages of the REMOP must be undertaken systematically and managed as a single project since all stages have to dovetail. The focus of the REMOP is to generate revenue by the final stage, but this is only achieved by systematically completing each of the earlier stages. In the cities Bo, Freetown and Kenema there were a number of attempts to contract out solely the collection of data However the results of those single stage projects resulted in many errors which negatively affected later REMOP functions.

3. Dedicated and well designed easy-to-use and update software working on standard off the shelf hardware is a central requirement. Administration efficiencies are significant and so the software design must handle the automation of records for all REMOP stages including valuation and billing.

a. Revenue Development Foundation engineer Jethro Buttner has developed sophisticated and well-integrated REMOP software. This has been enhanced after several upgrade iterations over the past nine years.

b. Central government Management Information Systems departments should be encouraged to adopt the software so that updating and servicing issues can be resolved. The adoption is still in progress in Sierra Leone but not yet commenced in Malawi.

c. The RDF software has been available free of charge for Councils to use provided that the REMOP process is followed closely. This has fostered a more accurate reporting and feedback of technical issues to resolve.

4. Essential sensitisation for the community, staff and councillors as well as dedicated capacity building for council staff is only really effective if undertaken on a learning by doing basis. Typically Council staff are not highly qualified, often due to salary constraints and thus in-house valuation expertise cannot not be expected. However some computer literacy can be expected. Workshops and manuals are useful but the day-to-day practice of dealing with local issues, community engagement and internal procedures can best be trained on a full time basis and in-situ. 
5. The implementation of the REMOP is initially a complex challenge but over time the process must become institutionalised and supported entirely by the councils. The required sustainability or institutionalisation of the program normally takes at least two full annual cycles. Typically the social contract between the council and the residents, often broken by historical non-performance and mistrust, needs to be rebuilt. The repair may only take place in the second year when the council can start to provide visible benefits. The extensive period of implementation has implications for funding. Improved revenue becomes established by year three fostering an adoption and institutionalisation by local councils where the staffing and administrative costs are sourced from the new internally generated revenue.

6. Traditional authorities such as the chieftaincy in Sierra Leone hold much standing with local populations, in particular the more rural communities. It is important to involve the chiefs throughout, particularly in the early stages. Although there is initial scepticism voiced by these authorities, they can be an effective ally of REMOP by demanding better services of the council.. This element is important in the encouragement and engagement of the community to participate.

7. Communication issues have consistently proved to be vital for all REMOP activities. Getting the message out to reach each segment of the community through a variety of medium encourages engagement, compliance and participation in the process of government.

8. Development aid agencies require long-term sustainability plans for their projects invested in local communities. Local councils are often the most appropriate partner to sustain these investments in the long term. By empowering and building capacity of local governments to achieve greater funds, they are better placed to be able to maintain and cover the operating costs of infrastructure etc provided by aid agencies. Thus typical infrastructure such as wells, waste management or sanitary improvements can be sustained. The KKKK project funded by IFAD was seen as an exit strategy for the funder.

9. Anecdotal evidence suggests other benefits to the areas where REMOP has been implemented. These include (i) longer-term impacts on local government accountability, (ii) better information flows to support urban planning and targeted service delivery, and (iii) indirect benefits through the quasiformalisation of property rights. 


\section{Next Steps}

Moving forwards there are a number of actions that should be implemented so that the REMOP program continues to function for local councils. Overall sharing the experiences at various government and nongovernment forums will foster improvements and advance the critical sustainability of internally generated revenue.

The following are key issues:-

1. Monitor the performance of local councils where the REMOP has been implemented not only for income but also for the delivery of benefits to the community. Additionally council feedback reporting on what in the REMOP process functions well, coupled with the reasons for any failures.

2. Strengthen the links with central government ministries of finance, local government or housing. It should be an objective to harness the support from central government. A less dependent sub-national government is their incentive where the national government plays an important co-ordination and monitoring role for management information. In Malawi it may be necessary to adapt legislation so that the REMOP approach can be aligned.

3. Encourage valuation surveyors to take part in the entire process of revenue mobilizsation and not just in the assessment of value. There is a need for the role of a revenue mobilisation officer at each of the councils. Trained valuation surveyors need to be encouraged to expand their traditional role into that of a more functional revenue mobilisaton officer.

4. Integrate the central government standardised reporting systems with REMOP revenues and accounts. The coordination and alignment of accounting will improve the adoption of REMOP across all councils.

5. Establishing links with polytechnic or higher learning institutions to have the subject of valuation and in particular REMOP courses. This will ensure a stable supply of students who can be seconded to councils for practical experience and eventual employment.

6. Improve and enhance the automation of the process. There are currently new technologies to aid the simplification and efficiency such as field data collection, payments through mobile phone, additional GIS functions. Additionally the REMOP software requires constant updating based on user experience and with a thrust on simplification, reporting standards plus additional functions such as statistical analysis.

7. Encouragement of other councils to adopt the program. While there appear to be many councils who require and request a REMOP service, there is a need for recognition by donors and governments. 